\title{
Nota sobre el libro Est Deus in nobis. Die Identität von Gott und reiner praktischer Vernunft in Immanuel Kants «Kritik der praktischen Vernunft» de Gerhard Schwarz ${ }^{1}$.
}

\section{Note on the book Est Deus in nobis. Die Identität von Gott und reiner praktischer Vernunft in Im- manuel Kants «Kritik der praktischen Vernunft» by Gerhard Schwarz}

\author{
IGNACIO FALGUERAS SALINAS \\ Universidad de Málaga (España)
}

\section{RESUMEN}

Este trabajo describe y examina críticamente la obra mencionada, cuya tesis final es la infinitud del hombre y su divinización por el Kant maduro. Su mérito consiste en (i) realizar una minu-

1 «Existe Dios en nosotros. La identidad de Dios y la razón pura práctica en la Crítica de la razón práctica de Kant». En lo que sigue abrevio el nombre del autor con las siglas «GS», y el de esta obra con las siglas «TGS». 
ciosa lectura de los postulados de la $K p V$, que permite descubrir una interna problematicidad no considerada antes, y (ii) proponer como solución a ella la existencia de una naturaleza dual en el hombre (homo phänomenon - homo noumenon). Aunque la obra adolece de ambigüedades tanto en las nociones básicas como en la tesis propuesta, eso no obsta para que sus aportaciones, de gran relevancia, deban ser tenidas seriamente en cuenta.

PALABRAS CLAVE

HISTORIA DE LA FILOSOFÍA MODERNA; I. KANT; POSTULADOS DE LA RAZÓN PRÁCTICA; DIOS; INFINITUD DEL HOMBRE; ANTROPONOMÍA.

\begin{abstract}
This note reviews and critically examines the book mentioned in its title. The main thesis of this book is the infiniteness and divinization of human being that can be found in the writings of the late Kant. The book examined has two merits: (i) by means of an exhaustive reading of the postulates of Kant's «Critique of Practical Reason», it manages to bring to light an internal inconsistency in these postulates; (ii) it proposes the existence of a dual nature in human being (homo phänomenon - homo noumenon) as the solution to that inconsistency. Though the book suffers from ambiguities and inaccuracy both in the basic notions employed and the main thesis advanced, it makes significant contributions that must be seriously taken into account.
\end{abstract}

KEY WORDS

HISTORY OF MODERN PHILOSOPHY, I. KANT, PRACTICAL REASON'S POSTULATES, GOD, HUMAN BEING'S INFINITENESS, ANTROPONOMY

PUblicAda POR LA EDITORIAL de la Technische Universität de Berlin, en 2004, esta obra recoge, ligeramente modificada, la tesis doctoral en filosofía defendida por el autor en la Facultad I de la Universidad Técnica de Berlín en junio de 2002, y que versa básicamente sobre la doctrina de los postulados de la inmortalidad y de Dios en la Crítica de la razón práctica $(K p V)$ de Kant. Se trata de un intento de reconstrucción del núcleo del pensamiento filosófico de Kant que revoluciona su interpretación usual.

Planteada de un modo más técnico-exegético que estrictamente filosófico, lo que en ella se propone el autor es verificar en los textos de Kant dos hipótesis encadenadas. La primera de ellas es la identificación de Dios con la razón pura práctica, la segunda es la identificabilidad de Dios y de la razón pura práctica con el hombre, de lo que se seguiría la infinitud de éste. Aunque ambas parecen sobradamente novedosas, en realidad lo absolutamente nuevo de esta tesis, más que tales enunciados en sí mismos, que tienen algunos precedentes parciales, es el intento de verificación de dichas hipótesis ya en la propia $K p V$, obra de madurez por excelencia, que es lo que nadie hasta GS había sostenido.

Perfectamente armada como argumentación técnico-científica, se puede decir que esta obra lleva a una perfección miniaturesca la trabazón de su estrategia demostrativa. Lo cual, sin duda, es muy valioso, pero deja en un segundo plano 
los problemas más hondamente filosóficos que generan sus propias aportaciones a la comprensión del conjunto del pensamiento de Kant, e incluso obscurece el pensamiento de su autor. Tanto es así que el lector tiene que poner mucho de su parte para procurar comprender filosóficamente lo que en verdad defiende GS. En concreto, el planteamiento de sus sucesivas hipótesis se hace por oposición a la que él llama la «tesis estándar», según la cual el hombre sería para Kant un mero ente finito, por lo que tanto él como la razón pura práctica se distinguirían de Dios. Tal planteamiento polémico hace perder nitidez a la exposiciones de GS, que a lo largo del escrito parecen sostener simple y llanamente la infinitud del hombre, pero cuya propuesta más matizada podría aclararse así: el hombre, para Kant, no es sólo un ente finito, sino también y sobre todo un ente no-finito, Dios mismo. Aparte de que, como se ve, la oposición con la tesis estándar no es completa, pues no se niega que el hombre sea un ente finito, la obscuridad gira en torno a la pretendida identificación del hombre con Dios. En efecto, su afirmación de la equivalencia entre la razón pura práctica con la voluntad pura, y de ésta con el sujeto humano, ${ }^{2}$ por una parte, y de la razón pura práctica con Dios, por otra, es tan rotunda que al final no se sabe bien si en definitiva la tesis que propone es que el hombre es finito y no-finito, o sola y positivamente infinito. Evidentemente, la tesis de la infinitud del hombre, si se toma sin ningún paliativo, como si el hombre fuera solamente infinito y todo él Dios, sería tan incompatible con el espíritu y la letra de toda la obra de Kant que anularía toda la aportación propiamente kantiana a la filosofía. No se olvide que en la $K p V$ se resume así la tarea crítica: «pero ese (conocimiento) no pertenece a una crítica de la razón práctica en general, la cual sólo tiene que indicar de un modo completo los principios de la posibilidad, de la extensión y de los límites de la razón práctica, sin referencia particular a la naturaleza humana». ${ }^{3}$ Si toda la tarea de la obra crítica de Kant consiste en poner límites al uso del entendimiento y de la razón práctica para no caer en la perplejidad, poniendo el énfasis en la limitación del entendimiento y de la voluntad humanas, parece que pretender que el hombre sea identificable directa y sencillamente con Dios sería una tesis abiertamente anti-kantiana, y la labor de esta tesis habría que entenderla, en consecuencia, como una destrucción del pensamiento propio de Kant hecha a partir de ciertas vaguedades del mismo.

2 «Aufgrund der Gleichsetzung der reinen praktischen Vernunft mit dem reinen Willen sowie des reinen Willens mit dem eigentlichen Selbst des Menschen, können die Identitätsthese und die Identifizierbarkeitsthese als ineinander transformierbare Sätze verstanden werden», TGS, 82 .

3 Vorrede, Kants gesammelte Schriften. Berlin: Königlich Preussischen Akademie der Wissensachften (Ak), 1902 ss., V, 8, líneas 20-23. Las cursivas de la traducción han sido introducidas por mí. 
Pero no tiene por qué ser necesariamente así. La letra de esta obra no sostiene que el hombre sea sola y positivamente infinito, sino que es, en la más alta de sus dimensiones, no-finito (infinitud negativa). Ahora bien, si GS no niega la finitud del hombre, y tan sólo se limita a afirmar su no-finitud, será porque el hombre es ambas cosas a la vez, aunque no bajo el mismo aspecto. Sin duda por eso la tesis contiene dos enunciados, uno en el subtítulo de la obra, en el que se identifican directamente Dios y la razón pura práctica, y otro en los desarrollos más prolijos de la tesis, en los que se propone la identificabilidad -no la identidad-, del hombre con Dios. Como expresión de lógica formal atemporal, la noción de identificabilidad carecería de sentido, pues o bien $\mathrm{A}=\mathrm{A}$, o bien No $A \neq A$. Lo cual hace pensar que esa expresión ha de ser entendida según la temporalidad, que está implícitamente contenida en la noción de posibilidad (identificabilidad). De acuerdo con lo anterior, este segundo enunciado parece que querría decir: el hombre no es idéntico con Dios en una determinada situación (este mundo, esta vida), pero puede llegar a serlo en otra (el mundo futuro, la vida futura).

Es más, creo que el título principal de la tesis (est Deus in nobis) da una pista sólida desde el principio para entender con cierta moderación la interpretación de Kant por GS. Es muy evidente que no se trata de una fórmula de identidad, pues en ella el enlace («est») entre «Deus» y «nobis» está mediado por un «in». En realidad, esa frase está tomada por Kant de los Nuevos Ensayos de Leibniz, en cuyo cuarto libro, cuando comenta el capítulo dedicado por Locke al entusiasmo, se introduce literalmente el «Est Deus in nobis». ${ }^{4}$ Kant lo conocía bien, y debió venirle a la memoria cuando estaba pensando en la posibilidad de una religiosidad sin la existencia de Dios. ${ }^{5}$ Como puede verse en el texto de Leibniz, el sentido de la frase no es el de una identificación con Dios, sino más bien el estar un hombre invadido y poseído transitoriamente por un espíritu divino -Leibniz menciona el caso del daimon de Sócrates-, pero siempre suponiendo una distinción entre lo divino y lo humano. En este sentido, el entusiasmo (del griego enthousiasmos o «endiosamiento») es entendido como bueno, mientras que quienes identifican su pensamiento con el divino dan lugar «entusiasmos» delirantes y peligrosos. Naturalmente, que Kant lo traiga a colación no quiere decir que por necesidad haya de tomarlo en el mismo sentido

4 Philosophische Schriften von Gottfried Wilhelm Leibniz. Berlin: Weidmann, 1875-1890, V, 487.

5 «Das Subject des categorischen Imperativs in mir ist ein Gegenstand dem Gehorsam geleistet zu werden verdient: ein Gegenstand der Anbetung (adoration) Dieses ist ein identischer Satz Die Eigenschaft eines moralischen Wesens das über die Natur des Menschen categorisch gebieten kann ist die Gottlichkeit desselben Seine Gesetze müssen gleich als göttliche Gebote befolgt werden. - Ob Religion ohne Voraussetzung des Daseyns Gottes möglich ist. est Deus in nobis», Opus Postumum (OP), Ak XXII, 129-130). Nótese el «über die Natur des Menschen». 
que Leibniz, aunque es obvio que, a tenor del texto en que se enmarca, algo tiene que ver con la religión. ${ }^{6}$ Sea cual fuere el sentido de la referencia de Kant, esa frase nunca puede ser interpretada como una fórmula de identidad directa entre Dios y el hombre. Entiendo, por tanto, que, si el autor ha querido destacar ese texto en el frontispicio de su obra, ha sido, precisamente, para indicar que su tesis no anula por completo la distinción entre Dios y el hombre, sólo sostiene su identificabilidad.

Por otro lado, las demás anotaciones del Opus Postumum que se citan en la Introducción, si se leen con todo su acompañamiento original, establecen que, aunque Dios está en nosotros, nosotros no somos idénticos con él. Dios -dice Kant- está en mí, es distinto de mí (causalmente) y obra en mí, juzgándome interiormente; ${ }^{7}$ en él vivimos, nos movemos y existimos, estimulados por el conocimiento de nuestro deber como mandato de Dios, y estando nuestra libertad sometida a las leyes coercitivas de la razón pura, por lo tanto estando ella por encima de nosotros $;{ }^{8}$ por eso, «solamente un Dios en mí, en torno a mí y sobre mí»; ${ }^{9}$ un ente que tiene poder ilimitado sobre naturaleza y libertad bajo leyes de la razón es Dios. ${ }^{10}$ Todas éstas son frases tomadas también del Opus Postumum

6 La postura de Kant ante el entusiasmo es compleja. Dice que es un afecto moral (Metaphysik der Sitten [MS], Ak VI, 409; Antropologie, Ak VII, 269), pero lo incluye también entre las fantastiquerías humanas (Reflexionen zur Anthropologie, Ak XV, 706, 812, 850). Lo vincula con la religiosidad (Vorlesungen über die Metaphysik [Pölitz],342), pero en la $K p V(\mathrm{Ak} \mathrm{V,157)}$ lo desaconseja como método para la educación de los niños. Hacia el final de su vida nos dice que el entusiasmo verdadero es sólo el que se dirige hacia lo ideal y puramente moral (Der Streit, Ak VII, 86).

7 «Es ist ein Wesen in mir was von mir unterschieden im Causal// Verhältnisse der Wirksamkeit (nexus effectivus) auf mich steht (agit, facit, operatur) welches, selbst frey d.i.ohne vom Naturgesetze im Raum und der Zeit abhängig zu seyn mich innerlich richtet (rechtfertigt oder Verdammt) und ich der Mensch bin selbst dieses Wesen und dieses nicht etwa eine Substanz ausser mir und was das befremdlichste ist: die Caussalität ist doch eine Bestimmung zur That in Freyheit (nicht als Naturnothwendigkeit)» (OP, Ak XXI, 25).

8 «In ihr, der Idee von Gott als moralische Wesen, leben, weben und sind wir; angetrieben durchs Erkentnis unserer Pflichten als Göttlicher Gebote. / Der Begriffvon Gott ist die Idee von einem moralischen Wesen welches als ein solches richtend allgemein gebietend ist. Dieses ist nicht ein hypothetisches Ding sondern die reine practische Vernunft selbst in ihrer Persönlichkeit und mit ihren bewegenden Kräften in Ansehung der Weltwesen und ihren Kräften. / Freyheit unter Zwangsgesetzen der reinen Vernunft» (OP, Ak XXII, 118). La cita implícita de s. Pablo (Hechos, 17, 28-29) puede encontrarse también en la correspondencia epistolar con Kant, Ak XII, 276, y en el $O P$, Ak XXII, 62.

9 «Gott ist nicht ein Wesen außer Mir sondern blos ein Gedanke in Mir / Gott ist die moralisch// practische sich selbst gesetzgebende Vernunft - Daher nur ein Gott in mir um mich und über mir» (OP, Ak XXI, 145).

10 «Ein Wesen was über Natur und Freyheit unter Vernunft// Gesetzen / unbeschränkte Macht hat ist Gott» (OP, Ak XXII, 117). 
-alguna de las cuales acompaña directamente a los textos elegidos por GS- y que declaran que Dios está por encima de nosotros y de nuestra libertad. Téngase en cuenta que en ellas no puede haber ningún tipo de ocultamiento o restricción mental por parte de Kant, pues son anotaciones escritas para sí mismo, que no estaban destinadas a ser publicadas. Sin embargo, esto no contradice la tesis de GS, siempre que sea entendida moderadamente.

Toda la fuerza argumentativa de esta obra de GS se apoya sobre una dificultad a primera vista insalvable, una verdadera antinomia práctica, que presentan los dos postulados de la $K p V$ : ambos comienzan exigiendo moralmente al hombre una santidad (postulado de la inmortalidad) y una realización del sumo bien en el mundo (postulado de la existencia de Dios), que a continuación son declaradas por Kant como inalcanzable e irrealizable, respectivamente, por el hombre en el mundo sensible. Ahora bien, según un principio moral universalmente reconocido, y citado por Kant, a saber: «ultra posse nemo obligatur», ${ }_{1}^{11}$ existiría una contradicción práctica entre la exigencia moral, u obligación de santidad y de producción del sumo bien, y la imposibilidad de su realización por el hombre, de tal manera que: si fuera imposible de realizar, entonces no cabría que estuviera obligado, o por el contrario, si es posible exigírselo, habrá también de ser posible realizarlo.

Para hacer frente a esta dificultad «sistemática» de los postulados, GS acude a lo que llama el modelo fundamental del hombre en Kant. Según el pensamiento kantiano, en el hombre se dan dos naturalezas, una sensible, otra suprasensible, ${ }^{12}$ por lo que se distingue entre dos hombres: el homo phänomenon y el homo noumenon. ${ }^{13}$ De acuerdo con esa distinción, el hombre total no es sólo el sensible ni sólo el suprasensible, sino que sería un hombre en parte sometido a las leyes del mundo sensible, en parte independiente del mundo sensible, en cuanto que sometido a las leyes morales. En expresión de GS, el hombre total sería un ente finito, pero según su dotación no-finito. Así resulta posible que el hombre, por ser homo noumenon, sea capaz de una exigencia superior a lo que alcanza el homo phänomenon, a saber, de una exigencia moral de perfección, si bien, mientras esté en situación de ente en el mundo sensible,

11 Zum ewigen Frieden, Anhang I, Ak VIII, 370. Cf. G. Achenwall, Iuris naturalis, pars posterior, liber II, §7, Ak XIX, 334. El enunciado más clásico era el de «ad impossibilia nemo tenetur», que puede encontrarse en A. G. Baumgarten, Initia philosophiae practicae primae, Sectio VII, Imputatio facti, $\S \S 131,138,142$, Ak XIX, 63-64, 66, 67, respectivamente.

$12 \mathrm{KpV}, \mathrm{Ak} \mathrm{V}, 43$, líneas 13 ss. Nótese que Kant habla de la naturaleza sensible y suprasensible de los entes racionales en general, entre los cuales está el hombre.

13 Por homo phänomenon entiende Kant, según GS, al hombre sometido por la sensibilidad a la heteronomía -tanto en el entendimiento como en la facultad de desear- de las leyes del mundo físico, mientras que por homo noumenon entiende al hombre moralmente autónomo bajo la razón pura práctica. 
no pueda realizar esa exigencia más que de modo aproximativo, mediante un progreso al infinito. ${ }^{14}$

Lo que inmediatamente viene a la mente del lector tras entender esta solución es que en ella se propone que el hombre no alcanzará la perfección moral, ni la felicidad merecida por ésta, mientras esté sometido a la heteronomía de las leyes físicas por su sensibilidad, o sea, durante esta vida, pero sí la podrá alcanzar en la vida futura, cuando esté libre de la sensibilidad. Aunque no recuerdo ninguno que lo afirme de modo rotundo, ciertos pasajes de la obra de GS podrían apuntar en ese sentido, ${ }^{15}$ cosa que, en cambio, los textos de Kant hacen abiertamente. ${ }^{16}$

A la dualidad de naturalezas del hombre correspondería, por otra parte, la distinción propuesta por GS entre una felicidad fenoménica y una felicidad nouménica, que tiene gran importancia para su interpretación del postulado de la existencia de Dios. En efecto, la obligación moral que tenemos de producir el sumo bien en el mundo implica la posibilidad de producir los dos componentes del sumo bien: la perfección moral y la felicidad. Y puesto que la perfección moral sólo sería plenamente realizable por el homo noumenon, también la felicidad adecuada a ella debería ser producible enteramente por él. Ahora bien, habida cuenta de que Kant reconoce que no se da un nexo necesario entre la moralidad y la felicidad sensible, para pensar la posibilidad de que la perfección moral pueda producir la felicidad resulta imprescindible suponer otro tipo de felicidad que no sea la sensible, sino que sea una felicidad nouménica producida por la voluntad buena o voluntad pura. El problema es que los textos publicados de Kant no hablan nunca de la felicidad nouménica, aunque en algunos de sus escritos no publicados y que corresponden a la época de elaboración de sus obras críticas (años 70-80) sí aparece tal distinción. K. Düsing interpreta que la ausencia de mención de esas distintas felicidades en los textos de las obras

14 TGS, 186-196.

15 «Zweitens, ist zu zeigen, dass Kants Rede von einen bloss möglichen Hervorbringung der intelligibilen Welt durch unseren (menschlichen) Willen als Konsequenz des Umstandes auffassen ist, dass wir (der Mensch) einen reinen Willen (noch) nicht verwirklicht haben, ihn aber verwirklichen können» TGS, 69; cf. Ibid., 142.

16 «Eben so ist die Seele des Menschen ausgerüstet mit Erkenntniß- und Begehrungskräften, mit Trieben und moralischem Gefühl, die gar keine hinreichende Bestimmung für dieses Leben haben. Da nun nichts umsonst ist, sondern alles I/ seinen Zweck hat; so müssen auch diese Fähigkeiten der Seele ihren bestimmten Zweck haben. Weil nun dieses im gegenwärtigen Leben nicht eintrifft; so тиß es für ein künftiges Leben aufbehalten seyn», Vorlesungen über die Metaphysik (Pölitz), Erfurt, 1821, reprographische Nachdruck, Darmstadt, 1988, 250. Y hablando del derecho al buen nombre y la fama tras la muerte, dice Kant: «wenn er als homo phaenomenon nicht mehr existirt» (MS, Ak VI, 295). Cf. Der Streit, Ak VII, 72-73. 
publicadas a partir de la $K p V$ refleja un cambio de pensamiento en Kant. ${ }^{17}$ Por el contrario, GS sostiene, con argumentos, que esa distinción permanece implícitamente contenida tanto en la antinomia de la razón práctica como en su solución y en el argumento de la existencia de Dios, así como en el resto de su obra posterior.

Finalmente, la interpretación de los argumentos de los postulados prácticos hecha por GS lleva consigo que haya de entenderse que nuestra razón, en cuanto que nouménica o pura, contenga el fundamento de la concordancia entre la felicidad fenoménica y la moralidad, y que en esa medida sea autora del mundo, y, por tanto, que nuestra razón pura haya de ser entendida como creadora de la naturaleza, es decir, como Dios. El homo noumenon y Dios serían, así, idénticos.

Con esto quedan expuestas, muy resumidamente, las razones de GS para sostener su tesis. Conviene ahora hacer notar las indudables ganancias de su obra, así como señalar algunas ambigüedades e imprecisiones que la empañan.

El principal logro de esta obra consiste en haber conseguido hacer una lectura fina y ajustada de la doctrina de los postulados de la $K p V$, resaltando algunos problemas latentes en ellos, y ofreciéndoles solución. Y tras haber destacado como fuente de los problemas y, por tanto, de su posible solución, la naturaleza dual del hombre, GS ha sabido caracterizarla en los textos de Kant como la dualidad homo phänomenon-homo noumenon, lo que constituye una gran ayuda para la comprensión filosófica de Kant. Es un acierto suyo haber encontrado en el par homo phänomeno-homo noumenon el ajuste temático de la distinción entre fenómeno y noúmeno, que había nacido como mera distinción metódica, y fue multiplicada por Kant en varios pares de ejemplos (mundo, república, virtud). Sin embargo, precisamente estas meritorias aportaciones necesitarían todavía, para ser completas y claras, de más puntualizaciones, pues en el conjunto de la tesis han quedado rodeadas de algunas ambigüedades e imprecisiones filosóficas, de las que entresacaré dos por su importancia.

La primera puntualización se refiere a una ambigüedad, a saber, la de que, habiendo propuesto un modelo dual para el hombre, el de homo phänomenohomo noumenon, sin embargo en el curso de sus razonamientos, aunque sin confesarlo del todo, GS pasa a sostener que la verdadera naturaleza del hombre es exclusivamente la nouménica. Lo explico un poco más.

Por una parte, al intentar resolver el problema, antes descrito, que presentan los postulados de la $K p V$, él hace hincapié en la necesidad de no dejar de considerar ninguno de los dos componentes naturales del hombre. Y eso mis-

17 K. Düsing, «Das Problem des Höchstens Guts in Kants praktischer Philosophie», Kant Studien LXII, 1971, 23-25, citado en TGS, 84-85. 
mo vuelve a acontecer cuando intenta explicar la «lógica» de la interpretación «estándar» mediante la teoría de lo que GS llama «Exkorporation», o sea, la expulsión de la razón pura -y de la voluntad pura- fuera del hombre. Lo que se propone con esta teoría es una identificación ( psicológica $^{18}$ ) de cada hombre con el homo phänomenon, de un calibre tal que no sólo le hace desconocer o dejar en el olvido su dimensión esencial de homo noumenon, sino que le incita a proyectarla fuera de sí mismo en un ente superior y distinto de sí (Dios). Para refutarla, acude GS al paradigma de la naturaleza dual del hombre. Parece, pues, que él debiera sostener que, si el hombre tiene una naturaleza dual, ésta ha de ser para siempre, de lo contrario, en vez de tener una naturaleza dual, su naturaleza sería doble en una situación (la actual), y sencilla en otra (la vida futura).

Por el contrario, en múltiples pasajes, así como en el conjunto de la tesis, el tenor de los textos parece sugerir que el hombre verdadero es sólo el hombre nouménico, sobre todo porque al identificar al hombre nouménico con la razón pura y con Dios parece incurrir en el error contrario, o sea, en considerar exclusivamente hombre sólo al homo noumenon, lo cual contradiría el modelo dual tanto como lo hace -según GS- la mencionada proyección del hombre nouménico fuera del hombre total: si el hombre en su totalidad está integrado por sus dos naturalezas a la vez, entonces la identificación con una sola de sus partes debería ser imposible. Por otro lado, una dilación de la identificación con Dios para la otra vida (identificabilidad) no resuelve filosóficamente el problema, pues no explica cómo, si ya somos esencialmente infinitos, podemos estar sometidos a las leyes de la finitud en esta vida.

He aquí, por tanto, unas cuestiones decisivas y no clarificadas por GS para matizar su modelo fundamental: ¿es dual la naturaleza del hombre o simple?, y si -como parece sostener- es dual, ¿lo es para siempre, o sólo lo es temporalmente? Aunque GS no se exprese de modo concreto y preciso respecto de ambas cuestiones -salvo de modo indirecto, como cuando afirma que el sumo bien no es un objeto híbrido, sino exclusivamente suprasensible ${ }^{19}-$, lo cierto es que las dos posibilidades contenidas en la última pregunta son hipótesis válidamente derivables de su interpretación, puesto que él, tras una detenida consideración de la noción de felicidad y de su distinción en fenoménica y nouménica, y

18 La llamo «psicológica», porque esa identificación no parece tener ningún otro fundamento en la filosofía kantiana. Si somos hombres nouménicos, no existe ninguna razón para que no lo sepamos por nosotros mismos, a no ser que nos «distraigan» algunas accidentales (e inexplicadas) propensiones (psicológicas) hacia el mundo fenoménico. De lo contrario, habría que pensar que Kant y quienes descubran el mundo inteligible serían hombres superiores, no sometidos a las mismas leyes heterónomas que los demás, esto es: en vez de ser dual cada hombre, habría dos tipos de hombre (superiores e inferiores).

19 TGS, 144-145. 
cuando está presentando el modelo kantiano sobre cómo tratar los fenómenos como noúmenos, afirma que la felicidad fenoménica de un ente racional puede ser considerada como un efecto de la libertad bajo las leyes morales, y, por tanto, noumenon..$^{20} \mathrm{Y}$ dado que los efectos sensibles de una causa nouménica serían, a la vez, fenoménicos y nouménicos, ${ }^{21}$ la libertad noumenon podría ser considerada, ya en esta vida, ${ }^{22}$ como causa posible de una felicidad completa (noumenon y phänomenon). Pero si eso se pudiera hacer en esta vida, aun teniendo el impedimento de la heteronomía, con mayor razón se podría hacer en una futura, lo cual supondría que la dualidad humana podría durar para siempre. En dicho caso cabría admitir un nuevo mundo sensible post mortem, pero tal que, en vez de estar nosotros sometidos a él, estuviera él -al ser creado por el homo noumenon- sometido a nosotros, de modo que, al menos, la felicidad a esperar en el mundo futuro podría cumplir el requisito de totalidad que literalmente Kant le exige. ${ }^{23}$

Los textos de Kant, sin embargo, no dan lugar a la posibilidad de que en esta vida podamos ser plenamente felices, como en cambio parece que creyeron los filósofos epicúreos y estoicos, ${ }^{24}$ pues -según él-nosotros tenemos que pensar la felicidad como futura; ${ }^{25}$ además, admitir dicha posibilidad equivaldría a eliminar la tensión necesaria que existe entre las dos naturalezas del hombre, o sea, a contravenir los planteamientos adoptados por GS. ${ }^{26} \mathrm{E}$, igualmente, la posibilidad de una vida futura en un mundo sensible es descartada de modo literal por Kant. ${ }^{27} \mathrm{Ha}$ de concluirse, por consiguiente, que las posibilidades abiertas por las interpretaciones de GS, aunque no sea ése su propósito, ${ }^{28}$ van más lejos que el pensamiento del propio Kant, y lo dejan sin determinar filosóficamente:

20 «Für die phaenomenale Glückseligkeit des vernünftigen Wesens ist deshalb festzustellen, dass sie aus der Perspektive des inteligiblen Selbstbewusstseins Wirkung aus Freiheit unter den moralischen Gesetz und damit Noumenon» TGS, 134.

21 TGS, 128.

22 «Eine solche Idee (der Unterschied zwischen einem gegenwärtigen und einem zukunftigen Leben) steht zwar in einem gewissenen Gegensatz zu der anderenorts von Kant vertretenen Aufassung, dass die inteligible Welt der Sinnenwelt 'schon itzt [jetzt]' zugrunde liegt»TGS, 143.

$23 \mathrm{KrV}$, A 806, B 834: «Glückseligkeit ist die Befriedigung aller unserer Neigungen (sowohl extensive der Mannigfaltigkeit derselben, als intensive dem Grade [und] auch protensive der Dauer nach)».

$24 \mathrm{KpV}, \mathrm{Ak} \mathrm{V}, 115$.

25 TGS, 143.

26 TGS, 260 y 263.

27 Cf.Der Streit, Ak VII, 72-73, donde además de mostrar como indeseable una vida futura con sensibilidad, se dice que incluso nuestro entendimiento, tal como es ahora, desaparecerá.

28 TGS, 17-18. 
si el hombre noumenon puede producir por sí mismo su felicidad, ${ }^{29}$ y somos ya ese homo noumenon, ¿por qué no admite Kant que podamos producir nuestra felicidad en esta vida?; y, si la pudiéramos producir en esta vida, siendo duales, ¿por qué tampoco admite que podamos ser duales en la vida futura?

La segunda puntualización hace referencia, más bien, a una grave imprecisión que se encuentra en el uso de la noción de identidad por GS, tanto cuando habla de ella directamente, como cuando habla de la identificabilidad del hombre con Dios. Sin salirnos del mero uso lógico del término, que es en el que se mueve $\mathrm{GS}^{30}$-y, por tanto, sin entrar en el terreno de la metafísica-, para que pueda hablarse de identidad ha de exigirse la biunivocidad o la intercambiabilidad total de dos proposiciones o de dos términos, de modo que: si $\mathrm{A}=\mathrm{B}$, entonces $\mathrm{B}=\mathrm{A}$; es decir, $\mathrm{A}$ y $\mathrm{B}$ han de ser entendidos como una sola y misma cosa, o un solo y mismo concepto. No cabe una identidad lógicamente verdadera que sea unilateral.

Esto supuesto, GS hace cuatro identificaciones que, al no ir acompañadas de aclaraciones, han de ser entendidas como biunívocas: 1) la de la razón pura práctica con la voluntad pura, 2) la de ambas con Dios, 3) la identificación de la razón pura práctica con la razón y voluntad puras del hombre,4) la identificación del homo noumenon con Dios. Si se las entiende como identidades estrictas o biunívocas, todas ellas son problemáticas y algunas claramente incorrectas.

Centrando la atención en las identificaciones claramente incorrectas, si Dios y la razón pura práctica fueran sencillamente intercambiables, entonces Dios debería ser un factum innegable, como lo es la razón pura para nosotros, ${ }^{31}$ y no podría ser un mero postulado de la razón práctica; o bien la razón pura práctica tendría que ser un postulado en vez de un factum. Dicho brevemente, todo el

29 El pensamiento de Kant es también en este punto ambiguo, porque si bien es verdad que sostiene que la buena voluntad ha de ser producida por uno mismo, lo cierto es que no se dice que esa buena voluntad produzca la felicidad, sino sólo el ser digno de ella (Reflexionen zur Moralphilosophie, Reflexio 7315, Ak, XIX, 313; KrV, A 806-809,B 834-837; KpV, Ak V, 110; KU, §87, Ak V, 450; Vorlesungen über die Metaphysik [Pölitz] 321-322; etc.). La idea de una autoproducción de la felicidad es inaceptable, sea en esta vida o en la futura, porque -habida cuenta de la noción de felicidad, que exige la completitud de los bienes y la satisfacción de todas las aspiraciones del ente racional, o sea, la «plenitud» del propio ser- nunca nadie puede producir su propia plenitud. En efecto, la plenitud no puede ser resultado de nada: o bien se posee por naturaleza (Dios), y entonces no se ha de producir, o bien, si tuviera que ser producida, sería porque se careciera de ella, pero entonces no podría producirla por sí solo aquel mismo que careciera de ella.

30 TGS, 62 y $63 ; 82 ; 272$.

31 «Die objektive Realität eines reines Willen oder, welches einerlei ist, einer reinen Vernunft ist im moralischen Gesetze a priori gleichsam durch ein Faktum gegeben» (KpV, Ak $\mathrm{V}, 55)$. 
planteamiento de la $K p V$ volaría por los aires: ¿para qué demostrar la existencia de Dios, si Dios fuera un factum?, ¿o acaso hace falta demostrar la existencia de la razón pura? Dios, dice Kant, es sólo una condición subjetiva que hemos de pensar como necesariamente objetiva con fines práctico-morales, es solamente un ideal que sirve para regular nuestra conducta, ¿son acaso meramente ideas la razón pura práctica y la voluntad pura? Es obvio que para el Kant de la $K p V$ no lo son, sino noúmenos con realidad objetiva, cosa que no acontece con la idea de Dios. La diferencia entre un factum y una condición subjetivamente necesaria es la diferencia que existe entre algo que sabemos que es objetiva e innegablemente real y algo en lo que subjetivamente necesitamos creer como real. Por tanto, en los planteamientos de Kant Dios y la razón pura práctica no son biunívocamente intercambiables. ${ }^{32}$

Tampoco puede admitirse, sin más, que la razón pura práctica, en Kant, sea biunívocamente idéntica con la razón pura práctica humana. Aun concediendo a GS, de acuerdo con algunos textos, que Kant iguala al homo noumenon con la razón pura práctica en nosotros, no podría admitirse, sin embargo, que en el pensamiento de Kant el homo noumenon sea idéntico con la razón pura práctica total. La razón de esta negativa radica en que Kant sostiene la posibilidad de la existencia de otros entes racionales en el universo, tanto finitos como nofinitos. Lo hace de modo expreso en varias de su obras de madurez,${ }^{33}$ como por ejemplo Idee zu einer allgemeinen Geschichte, donde dice que pueden habitar en otros planetas seres racionales capaces, quizás, de alcanzar completamente su destinación en vida, cosa que nosotros los hombres individuales no podemos hacer, sino que sólo el género humano puede esperarlo. ${ }^{34}$ No debe, por tanto, igualarse biunívocamente el «ente racional» con el homo noumenon, el cual es ciertamente racional, pero no agota la racionalidad posible. El homo noumenon es entendido por Kant como la Menschheit ${ }^{35}$, o sea, como la esencia ideal del

32 En el $O P$ dice Kant lo siguiente: «Die bloße Idee von Gott ist zugleich ein Postulat seines Daseyns. Ihn sich denken und zu glauben ist ein identischer Satz» (Ak XXII, 109). En este texto se toman como equivalentes la idea de Dios y el postulado de su existencia, o pensar a Dios y creer en él; pero no he encontrado ninguno en que se haga de la razón pura práctica una mera idea o un postulado. Cf. Ibid., 61.

33 KU, §91, Ak V, 467; Anthropologie, Ak VII, 321, 331, 332; Logik, §84, Ak IX, 133 en nota.

34 Idee, Ak VIII, 23 en nota: «Die Rolle des Menschen ist also sehr künstlich. Wie es mit den Einwohnern anderer Planeten und ihrer Natur beschaffen sei, wissen wir nicht; wenn wir aber diesen Auftrag der Natur gut ausrichten, so können wir uns wohl schmeicheln, daß wir unter unseren Nachbaren im Weltgebäude einen nicht geringen Rang behaupten dürften. Vielleicht mag bei diesen ein jedes Individuum seine Bestimmung in seinem Leben völlig erreichen. Bei uns ist es anders; nur die Gattung kann dieses hoffen».

35 MS, Ak VI, 239; Metaph. der Sitten (Vigilantius), citado en TGS, 252; Der Streit, Ak 
hombre ${ }^{36}$, que, siendo enteramente racional, podría corresponderse con el género humano, pero no pasaría de ser la razón pura práctica en nosotros, no llegaría a ser la razón pura práctica total. En confirmación de lo que digo, también la $K p V$ afirma en varios pasajes que el ser entes racionales no es un privilegio exclusivo de los hombres ${ }^{37}$. De todo lo cual se deduce que, si bien el hombre participa de la razón pura, la razón pura no se reduce al homo noumenon. Si esto es así, entonces la tesis de GS se precipita al identificar biunívocamente la razón pura práctica con la razón y la voluntad humanas, siendo aquélla más amplia que la nuestra.

Por último, aún es menos posible que el hombre se identifique biunívocamente con Dios. ${ }^{38}$ Ante todo porque Dios en Kant es una mera idea, un pensamiento (Gedanke) sin correspondencia real objetiva, y el hombre es un objeto real y el sujeto del pensamiento; además, en tanto que el hombre sea dual, no podrá identificarse con Dios, que no lo es. Es cierto que la autonomía moral del hombre es llevada por Kant hasta el punto de considerar que somos moralmente responsables ante nosotros mismos ${ }^{39}$, pero eso no es bastante para concluir una identidad recíproca entre el hombre y $\operatorname{Dios}^{40}$. Incluso si consideráramos sólo la

VII, 254; Nachlass, Ak VII, 413.

36 Anthropologie, Ak VII, 321.

37 «Es schränkt sich also nicht blos auf Menschen ein, sondern geht auf alle endliche Wesen, die Vernunft und Willen haben, ja schließt sogar das unendliche Wesen als oberste Intelligenz mit ein» (Ak V, 32, líneas 15 ss.). Cf. KpV, Vorrede: «...diese aber gehört nicht in eine Kritik der praktischen Vernunft überhaupt, die nur die Principien ihrer Möglichkeit, ihres Umfanges und Grenzen vollständig ohne besondere Beziehung auf die menschliche Natur angeben soll» (Ak V, 8 línea 20 ss.).

38 Habría sido deseable que el autor estableciera la noción o nociones de Dios antes de identificarla con ninguna otra cosa, pues el concepto de Dios en Kant es multifacético: podría decirse que recoge lo más alto e ideal que encuentra él en cada región de lo humano, pero sin sobrepasarlas del todo nunca, porque sus planteamientos subjetivistas se lo prohíben.

39 Yo mismo, en mi libro Perplejidad y Filosofía trascendental en Kant (Pamplona: Cuadernos de Anuario Filosófico, nº 71 ,1999), he afirmado que Kant hace del mundo y de Dios meras dimensiones de la razón humana (146); y que, según Kant, en virtud de la autonomía moral, el hombre es responsable ante sí mismo (127 nota), o que «La filosofía trascendental es un constructo humano por el que [el hombre] se hace a la vez autor de sí mismo» (145). Sin embargo, nada de eso implica una identidad biunívoca con Dios.

40 Kant distingue sutilmente entre la ley, el legislador-autor de la ley y el que tiene el poder de imponerla de modo vinculante. Dios es, para Kant, no el autor de la ley, sino aquel cuya voluntad la impone (la razón universal), mientras que nosotros podemos ser autónomos sólo en cuanto que somos autores de la ley, pero no de su obligatoriedad (MS, Ak VI, 227). Nuestra autonomía consistiría, según él, en auto-legislarnos, pero no en auto-obligarnos. Dios, en cambio, es la idea de un legislador que obliga a todos, pero no está obligado a nada. Nuestra razón es sólo el medio por el que la razón universal nos impone su obligatoriedad, a la que podemos libremente obedecer o no. Si se identificara biunívocamente la razón vinculante (universal) con 
esencia del hombre, tampoco podrían identificarse biunívocamente, pues si el homo noumenon, que es -según GS-lo inmortal en nosotros, fuera directamente Dios mismo ya en la $K p V$, entonces no habría razón alguna para distinguir en ella entre el postulado de la inmortalidad y el de la existencia de Dios: con probar lo primero ya habríamos probado lo segundo. De nuevo nos encontraríamos no ya con un problema filosófico serio, sino con que el planteamiento entero de esta obra de Kant resultaría demolido.

Por lo demás, ¿qué sentido tiene que un mero pensamiento pensado (Dios) sea enteramente equivalente con una facultad (razón práctica), y ambos lo sean con el hombre pensante (Selbst), y viceversa? Y si pretende que tenga algún sentido, debería haber sido expuesto por el autor.

En suma, si en la $K p V$ la razón pura práctica no es biunívocamente intercambiable con Dios, y el hombre tampoco es biunívocamente intercambiable con la razón pura práctica, entonces en ella la consecuente intercambiabilidad biunívoca entre el hombre y Dios ha de ser imposible.

El autor de este libro no considera ninguna de las graves dificultades señaladas, que afectan al núcleo mismo de su tesis, y que es necesario afrontar para entenderle a él y a Kant. Por esa razón sugerí, al principio, que el trabajo de GS -sin negar su valor filosófico-, es más técnico-científico que filosófico. Y nótese que para evitar las dificultades señaladas no basta con decir, como hace GS, que Kant, por las razones que fuere, no quiso exponer con toda claridad en su obra publicada su verdadero pensamiento, ${ }^{41}$ pues al afectar al mismísimo planteamiento formal de la $K p V$ ya no estaríamos ante una mera ocultación de su pensamiento -por lo demás, muy poco ilustrada ${ }^{42}$, sino ante una patente manipulación de sus lectores.

Con lo anterior no sugiero que sea imposible encontrar algún sentido kantiano a las tesis de GS, sino tan sólo que -si no se añaden aclaraciones ulteriores- tal como están expuestas generan problemas mayores que los que resuelven. Se me ocurren, varias posibilidades de «adaptación» de las tesis de GS al pensamiento de Kant en sus escritos publicados. La primera sería la de entender la identidad de una forma más relajada que la de GS, para lo cual se encuentran oportunidades suficientes en la obra de Kant. Aunque GS suscriba una interpretación estricta de la identidad, él mismo alude, muy de pasada, a la existencia de una interpretación laxa o débil de la identidad con fundamento

la razón vinculada (humana), nadie podría desobedecer a la ley moral.

41 TGS, 266-267.

42 La insistencia de Kant en la publicidad del juicio de la razón, propia de la ilustración ( $K r V, 1$. Vorrede, A XI, en nota; Was ist Aufklärung?, Ak VIII, 37), quedaría traicionada por el simple ocultamiento de sus juicios; pero la manipulación sería, adicionalmente, inmoral. 
en A. G. Baumgarten, el maestro de Kant. ${ }^{43}$ Pero el propio Kant habla en sus obras de muchos tipos de identidad: una identidad numérica, una identidad real u objetiva, una identidad lógica o «analítica», una identidad implícita y otra explícita (tautología), una identidad total y una identidad parcial, e incluso habla de una identidad que podríamos llamar «analógica». ${ }^{44}$ Es indudable que antes de sostener la tesis de la identidad habría sido necesario hacer un estudio detenido de la misma en Kant, quien, en parte, toma la noción de Baumgarten, pero, indudablemente, la modifica y adecua a su planteamiento crítico, de modo que no es tan sencilla como pudiera parecer. La equivalencia, que defiende GS, entre el homo noumenon y la razón pura práctica, y, en consecuencia, entre el homo noumenon y Dios ¿no podría ser entendida como una equivalencia analógica, o al menos como una equivalencia parcial? Es verdad que Kant rechaza que el hombre y Dios caigan bajo un mismo género, ${ }^{45}$ pero ¿no cabría interpretar el sentido de ese rechazo como restringido a la habilidad técnico-artística del hombre - que nada tendría en común con la actividad creativamente más alta-, de modo que admitiera, en cambio, una comunidad de género con Dios en el campo moral? $?^{46}$

Otra posibilidad, que podría complementar a la anterior, sería la de entender que para Kant no existe más que una razón pura práctica o una voluntad pura, personificada por nuestro pensamiento en el ideal de Dios, de tal modo que ella operara en todos los entes racionales, los cuales serían, por su parte, receptores pasivos de la actividad de aquélla, a la que sólo podrían o bien poner impedimentos, o bien dejarla actuar en sí mismos. En su filosofía de la historia Kant propone que el sujeto de la historia es el género humano, no los individuos, ¿no podría pensarse que el sujeto de la racionalidad fuera, para él, también general ${ }^{47}$

$43 T G S, 62$ en nota 132. De que el autor entienda su tesis de la identidad como identidad lógico-analítica queda constancia cada vez que dice que sus tesis han de ser entendidas como juicios explicativos (Erläuterungsurtheile) de los postulados, pues precisamente ésa es la descripción que hace Kant de la identidad lógica ( $C f . K r V$, A7, B10-11).

$44 \mathrm{KU}, \S 90, \mathrm{Ak} \mathrm{V}, 464$ en nota; cf. Ibid., §87, Ak V, 456; Logik, §84, Ak IX, 132-133.

$45 K U, \S 90, \mathrm{Ak} \mathrm{V}, 464$ en nota.

46 Cf. OP, Ak XXII, 61: «Ist der Begriff von Gott ein Gattungsbegriff (Species) von Wesen deren mehrere von derselben Art gedacht werden konnen entweder neben einander (collectiv) oder einer anstatt des anderen disjunctiv (conceptus vel singularis vel communis). Im letzteren Falle würden Götter gedacht werden die als Sinnenwesen wenn man sich an ihnen einen Gegenstand der Verehrung denckt den Nahmen der Götzen führen würden d.i. den von Göttern die der Mensch selbst zu diesem Range willkührlich und abergläubisch erhebt».

47 «Weil aber der Begriff von Gott der vom höchsten Wesen überhaupt (ein Maximum) mithin auch Einzigen enthält so ist die zu lösende Aufgabe nur die:... Ist ein Gott? (es sey hiedurch ein Gattungsbegriff nomen proprium nicht appellativum nach welchem es mehrere dieser Art geben konnte oder als conceptus singularis, individuum, da er zugleich als Einiger gedacht wird)» $O P, \mathrm{Ak}, \mathrm{XXII}, 61$. 
y, en cuanto tal, idéntico para todos los entes racionales, que serían meros aplicadores de la racionalidad universal? Se trataría, en ese caso, de una peculiar reedición del averroísmo, ${ }^{48}$ aunque en un campo no meramente intelectual, sino en el de una razón universal de índole práctica. Naturalmente, esta posibilidad generaría graves conflictos para una verdadera libertad personal.

Adicionalmente, y dejando de lado la posibilidad de una solución de inspiración netamente espinosista -dado que Kant se opone a ella reiteradamente ${ }^{49}$ y que, además, invalidaría el factum originario de la libertad-, por lo menos cabría pensar en la posibilidad de una «adaptación» del estilo de la que proponen sus discípulos idealistas (Fichte y el primer Schelling), o sea, una mezcla de espinosismo y criticismo, según la cual lo divino podría ser una dimensión (la más alta) del hombre, pero tal que, a la vez, lo más alto del hombre fuera una parte de Dios cualitativamente homogénea con él, si bien para poder pensarlo seriamente habría de ser desarrollada una cierta especulación reflexiva, de la que no he hallado trazas en Kant. ${ }^{50}$ Por esa razón, algunos piensan que quizás ciertas anotaciones del Opus Postumum pudieran deberse al influjo de dichos discípulos. Pero, en cualquier caso, esta posibilidad obligaría a entender a Kant no de modo meramente sistemático, sino de modo histórico, es decir, admitiendo cambios de pensamiento entre la $\mathrm{KpV}$ y el Opus Postumum, tal como otros autores ${ }^{51}$ sostienen.

Como se ve, tales posibles adaptaciones no dejan de tener dificultades, y, sobre todo, no eliminan los problemas de fondo del pensamiento de Kant. Por eso, aunque las tesis de GS estén faltas de los matices necesarios, tienen un

48 Cf. L. Polo, Sobre la existencia cristiana. Pamplona: Eunsa, 1996, 94-98.

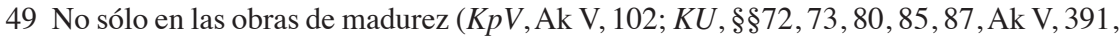
393, 421,439; Was heisst: Sich in Denken orientieren?, Ak VIII, 143 en nota), sino incluso en el $O P:$ «NB. Nicht daß wir wie Spinoza wähnt in der Gottheit anschauen sondern umgekehrt daß wir unsern Begriff von Gott in die Gegenstände der reinen Anschauung in unseren Begriff der transsc. Philosophie hinein tragen» (Ak, XXII, 59).

$50 \mathrm{El}$ sistema kantiano es meramente formal, mientras que la sistematicidad que propugnan sus discípulos quiere reunir la forma con los contenidos, o sea, construir el sistema total, pero esto requiere un peculiar pensamiento especulativo que he descrito en varios de mis trabajos: La 'res cogitans' en Espinosa, Pamplona: Eunsa, 1976, 142 ss.; «La noción de sistema en Schelling», en I. Falgueras (edit.) Los comienzos filosóficos de Schelling, Málaga: Servicio de Publicaciones de la Universidad de Málaga, 1988, 31-66; «La especulación moderna», Prólogo al libro de J. J. Padial , La Idea en la Lógica de Hegel, Málaga: Servicio de Publicaciones de la Universidad de Málaga, 2003, 17-50; «Lógica formal, lógica de contenidos y tiempo en Hegel», en I. Falgueras, J. García, J. J. Padial (coords.) Yo y tiempo. La antropología filosófica de Hegel, Málaga: Servicio de Publicaciones de la Universidad de Málaga, 2010, vol. I, 63-86.

51 Como R. Wimmer, B. Tuchling, E. Förster, A. Cortina, G. B. Sala, citados en TGS, 11-14. 
indudable efecto revulsivo, beneficioso para renovar y sanear la comprensión de la filosofía kantiana.

La aportación de la obra de GS, por razón de la cual es obligado tomarla en consideración, estriba en el descubrimiento de graves problemas que afectan al pensamiento teológico-moral de Kant y sobre los que se pasa generalmente la mirada sin prestarles la atención debida. La colección de textos kantianos que aporta al respecto no puede ser ignorada, pues introduce indicaciones que ponen a prueba la manera común de entenderlos, y demuestran lo obscuros e indeterminados que son algunos planteamientos radicales de su filosofía. Si creo imprescindible el conocimiento de esta obra para los expertos en Kant, es porque en ella se llevan a un cierto extremo las consecuencias de algunos textos fundamentales suyos, y que ponen en cuestión el sentido último de todo su filosofar. La interpretación dada por GS a los postulados de la $K p V$ reclama la atención de los investigadores, muy poderosa y atinadamente, sobre el tránsito desde la tarea meramente crítica a una intensificación de la filosofía trascendental, tránsito que está pendiente todavía de ser elucidado.

IGNACIO FALGUERAS SALINAS es Catedrático de Filosofía en la Universidad de Málaga.

Lineas de investigación:

Filosofía moderna, idealismo alemán, antropología, la filosofía de Leonardo Polo.

Publicaciones recientes:

(1999) Perplejidad y filosofía trascendental en Kant, Cuadernos de Anuario Filosófico, Universidad de Navarra, Pamplona.

(1999) El abandono final. Una meditación teológica sobre la muerte cristiana, Universidad de Málaga, Málaga.

Dirección electrónica: jifalgueras@uma.es 
